https://helda.helsinki.fi

\title{
The welfare ranking of prices and quantities under noncompliance
}

\section{Lappi, Pauli Antero}

2016

Lappi , P A 2016 , ' The welfare ranking of prices and quantities under noncompliance ' , International Tax and Public Finance , vol. 23 , no. 2 , pp. 269-288 . https://doi.org/10.1007/s10797-015-9356-1

http://hdl.handle.net/10138/229637

https://doi.org/10.1007/s10797-015-9356-1

acceptedVersion

Downloaded from Helda, University of Helsinki institutional repository.

This is an electronic reprint of the original article.

This reprint may differ from the original in pagination and typographic detail.

Please cite the original version. 


\title{
The welfare ranking of prices and quantities under noncompliance
}

\author{
Pauli Lappi*
}

\begin{abstract}
We study the welfare ranking of an emission tax and emissions trading when firms self-report their emissions to the regulator and may be noncompliant. We allow for the subjective probabilities of auditing, and using conventional assumptions find that an emissions tax produces a higher level of welfare than emissions trading under noncompliance. The main driver of the result is that the compliance pattern of the firms affects the marginal compliance cost (price of emissions) in the case of permits, thus affecting the level of emissions and welfare. The result also holds when enforcement and sanctioning costs are taken into account and differs from the result found by Montero (2002, Journal of Public Economics). We also show that the ranking may be reversed if these costs are taken into account and the regulator must audit at least one firm. We also analyze the welfare ranking when the expected penalties depend on relative violations.

Keywords: Emissions trading, emission taxes, compliance, monitoring, enforcement costs, sanctioning costs. JEL codes: H23, Q50, Q58.
\end{abstract}

\section{Introduction}

We study the effects of noncompliance on the welfare obtained with an emission tax or with emissions trading. In particular, we analyze the welfare difference between these instruments under noncompliance and take into account the enforcement and sanctioning costs that affect the welfare in addition to the total emissions. Contrary to the existing

${ }^{*}$ University of Helsinki, Department of Economics and Management. Address; Latokartanonkaari 9, Helsinki, Finland; e-mail pauli.lappi@helsinki.fi; telephone +358 50415 1227; fax number +358 9191 58096 
literature, we find that the level of welfare is higher with an emission tax than with emissions trading with one exception: if the regulator must monitor at least one firm, the welfare ordering may be reversed. To our knowledge, only Montero (2002) has studied the welfare difference between these instruments under noncompliance. ${ }^{1}$ This is surprising since this comparison is perhaps the most basic comparison of instruments that can be studied. $^{2}$

In the models presented in this paper and in the literature on noncompliance, one of the key modeling choices is related to the expected penalties, or in particular to choices about auditing probabilities and penalty functions. The literature can be roughly divided into two parts, depending on the assumptions made about the auditing probability function that the firms employ in optimization. While in the first set the probability of auditing is assumed to be an objective probability, ${ }^{3}$ the second set of literature postulates a subjective probability. ${ }^{4}$ An objective probability refers to a situation in which the auditing probability that the firms use is known by the regulator. A subjective probability refers to a case where the firm forms expectations on the risk that it will be selected for a closer inspection, perhaps based on its choices, such as a violation. When the probability is subjective, the regulator does not know the probability of auditing that the firm uses in its optimization. ${ }^{5}$

\footnotetext{
${ }^{1}$ Montero's model is used in Rohling and Ohndorf (2012) to analyze the effect of fiscal cushioning in the choice between emissions trading and emission tax. They found evidence in favor of emissions trading.

${ }^{2}$ The existing literature on noncompliance and on the comparison of different instruments has mainly focused on enforcement costs (Malik 1992), emission levels (Keeler 1991) and on the incentives to adopt new abatement technology (Arguedas et al. 2010, Villegas-Palacio and Coria 2010).

${ }^{3}$ This assumption is used, for example, in Malik (1992), Stranlund and Dhanda (1999), Montero (2002), Macho-Stadler and Pérez-Castillo (2006), Stranlund (2007), Stranlund, Chávez, Villena (2009) and Stranlund and Moffitt (2014).

${ }^{4}$ For example, Malik (1990), van Egteren and Weber (1996), Malik (2002), Hatcher (2005) and Hatcher (2012).

${ }^{5}$ For example, a firm may think that its choice of violation affects the chance for the firm to belong to the set of audited firms. This is something like speeding on the motorway; the probability of the police stopping you is essentially subjective and may depend on how much over the limit you are speeding.
} 
This modeling choice is important in general, since for example, it is known from the literature (see, for example, Stranlund and Dhanda (1999)) that using (objective) probabilities leads to a simple condition characterizing the compliance decision: a firm is compliant if and only if the marginal expected penalty at zero violations is greater than or equal to the permit price (or the level of tax). This knowledge can be exploited by the regulator to induce full compliance. To clarify, with full information about the costs and damages of emissions, this possibility allows the first-best choice of emissions with an emission tax or with emissions trading. But when subjective probabilities are assumed, the regulator cannot design enforcement such that compliance by every firm can be guaranteed simply because the regulator cannot know how large the marginal expected penalty at the zero violation level is. Since the subjective probability may coincide with the objective probability (which may simply be the number of audited firms divided by the total number of firms), the objective probability is a special case of the subjective probability. As Sandmo (2002) writes, "the properties of the probability functions reflect the beliefs of the firms with respect to the nature of public environmental policies and these beliefs are essentially subjective." ${ }^{6}$ For these reasons we focus on firm behavior assuming subjective probabilities, but the results obtained in the study may be extended to encompass the objective probability of auditing (if the expected penalties are such that some of the firms are noncompliant).

Another relevant distinction related to the expected penalty function is between absolute and relative violations. Do the expected penalties depend on the level of absolute violations, namely on the difference between actual and reported emissions? Or do penalties depend on relative violations, namely on the ratio between absolute violations and reported emissions? This choice is not restricted only to subjective probabilities, where a firm may see that the auditing probability depends on either of the two types of violations,

\footnotetext{
${ }^{6}$ From page 91.
} 
but may also be relevant for the objective probability case. ${ }^{7}$

In this paper we first analyze the welfare difference with absolute violations assuming that the instruments are chosen by a regulator presuming full compliance. ${ }^{8}$ We find that taxes produce a higher welfare level than permits. This result is essentially due to the asymmetrical effect that noncompliance has on the price of compliance, depending on which instrument is chosen. With a tax the price is independent of the compliance pattern among the firms, but with permits the price depends on the number of compliant firms, thus affecting the actual total emissions and the welfare level.

We then allow the regulator to choose the instruments and the number of audited firms optimally without assuming full compliance. In this case we also supplement the welfare criterion with enforcement and sanctioning costs. ${ }^{9}$ We show that these modifications leave the welfare ranking intact: taxes yield a higher level of welfare than permits under noncompliance. The result for permits show a trade-off between the actual total emissions and the number of audited firms which is not present with emission tax. When the emission tax is used, the first-best tax level is enough to yield the first-best emission level, thus allowing the regulator to save on the auditing expenses by auditing fewer firms than with emissions trading. Montero (2002) finds that under certainty about cost and benefit curves, the instruments yield the same level of welfare. The difference between his finding and those of this paper stems from different modeling choices: Montero assumes that the auditing probability is objective and constant in violations, but we assume that the probability is subjective and nondecreasing in violations. Our assumptions are more

\footnotetext{
${ }^{7}$ As Hatcher (2012) explains, expected penalties may depend on the relative violations, since penalties in addition to probabilities may depend on the relative violations.

${ }^{8}$ Throughout we assume that the firms must self-report their emissions to the regulator. For example, in the EU-ETS, self-reporting is carried out during accredited inspections and compliance checks by the competent authority.

${ }^{9}$ We assume throughout the paper, that the regulator can commit to the monitoring scheme and that the firms regard the scheme credible. See Franckx (2002) for an analysis of the case where the regulator cannot commit to the auditing probability it sets.
} 
general. Furthermore, we find that if the regulator's problem is constrained by the requirement to audit at least one firm, it may actually reverse the welfare ranking between the instruments. For the reversion to occur, it is necessary that the unit sanctioning cost is high enough.

We finally extend the analysis and allow the expected penalties to depend on the relative violations. ${ }^{10}$ The independence of actual emissions from the compliance choice, when a tax is used as the instrument, is a feature of absolute violations, and it does not hold when we allow relative violations. Therefore, we analyze the welfare difference in this case as well. We find that the previous welfare result holds when the regulator chooses the instruments assuming full compliance and when the enforcement and sanctioning costs are left out of the welfare criterion.

We continue the paper with a general set-up regarding the basic assumptions and notation. Then we analyze absolute violations and the welfare difference. In section 3 we study the relative violations. The last section concludes.

\section{A welfare analysis under noncompliance: Absolute violations}

The basic notation used is as follows. We analyze a sector with $n$ risk neutral firms indexed by $i, i=1, \ldots, n$. The benefit (or the profit) from emissions $e_{i}, \pi_{i}\left(e_{i}\right)$, has the properties $\pi_{i}^{\prime}\left(e_{i}\right)>0$ and $\pi_{i}^{\prime \prime}\left(e_{i}\right)<0$. In this set-up emissions can be reduced through abatement investments or through output reductions and both have a similar effect on the objective function. When emissions trading is used as the instrument, the profit function of firm $i$ is

$$
\Pi_{i}^{p}\left(e_{i}, \hat{e}_{i}\right)=\pi_{i}\left(e_{i}\right)-p\left(\hat{e}_{i}-e_{i}^{0}\right)-S_{i}\left(v_{i}\right),
$$

\footnotetext{
${ }^{10}$ Most of the research has assumed absolute violations. To our knowledge, only Hatcher $(2005 ; 2012)$ and Rousseau and Proost (2005; 2009) have analyzed relative violations.
} 
where $\hat{e}_{i}$ are the reported emissions, $e_{i}^{0}$ is the initial allocation of permits, and $p$ is the price of the permits. The profit function includes the expected penalty function $S_{i}$, which depends on the level of absolute violations $v_{i}:=e_{i}-\hat{e}_{i} \geq 0 .{ }^{11}$ The expected penalty function is the product of the auditing probability $\sigma_{i}\left(v_{i}\right)$, and the penalty $m_{i}\left(v_{i}\right)$. We assume that the auditing probability function is subjective and satisfies properties $\sigma^{\prime}\left(v_{i}\right) \geq 0, \sigma^{\prime \prime}\left(v_{i}\right) \geq 0$ and $\sigma(0)>0 .{ }^{12}$ The penalty function satisfies properties $m_{i}^{\prime}\left(v_{i}\right)>0$, $m_{i}^{\prime \prime}\left(v_{i}\right)>0$ and $m_{i}(0)=0$. Note that the marginal penalty is strictly increasing, which means that we have excluded the possibility of constant marginal penalties. ${ }^{13}$ With these assumptions the expected penalty function $S_{i}$ is strictly increasing, strictly convex and zero when $v_{i}=0$. Throughout the study we denote the compliant emissions level with $e_{i}^{h}$ and the noncompliant emissions level with $e_{i}^{d}$.

The same assumptions about auditing probabilities and penalties are also used when an emission tax is the policy instrument. In this case the profit function for firm $i$ is

$$
\Pi_{i}^{t}\left(e_{i}, \hat{e}_{i}\right)=\pi_{i}\left(e_{i}\right)-t \hat{e}_{i}-S_{i}\left(v_{i}\right)
$$

where $t$ is the emission tax.

\subsection{The welfare analysis without enforcement and sanctioning costs}

We start by analyzing emissions trading. Since partial equilibrium is assumed, we use the following definition for market equilibrium:

\footnotetext{
${ }^{11}$ Relative violations are discussed in section 3 .

${ }^{12}$ These assumptions are similar to the ones made in van Egteren and Weber (1996) and Malik (2002). Sandmo (2002) thinks that it is more realistic to allow the auditing probability to depend on the level of violation. Also, among many others, Harford (1978) and Rousseau and Proost (2005; 2009) assume that the auditing probability is increasing in violations.

${ }^{13}$ Sandmo $(2002)$ sees $m_{i}^{\prime}\left(v_{i}\right)>0$ and $m_{i}^{\prime \prime}\left(v_{i}\right)>0$ as "natural" assumptions. If we allowed $m_{i}^{\prime \prime}\left(v_{i}\right) \geq 0$, we should also analyze corner solutions. However, we are only interested in interior solutions.
} 
Definition 1. Permit market equilibrium is a vector $\left(\hat{e}_{1}, \hat{e}_{2}, \ldots, \hat{e}_{n}, p, E^{0}\right)$ such that the following two conditions are satisfied simultaneously:

1. The reported emissions $\hat{e}_{i}, i=1, \ldots, n$, are such that

$$
\left(e_{i}, \hat{e}_{i}\right)=\operatorname{argmax}\left\{\pi\left(e_{i}\right)-S_{i}\left(v_{i}\right)-p\left(\hat{e}_{i}-e_{i}^{0}\right) \text { such that } v_{i} \geq 0\right\} .
$$

2. The permit market clears, that is $\sum_{i=1}^{n} \hat{e}_{i}=E^{0}$ for some $p$.

Here the total initial allocation of permits, $E^{0}=\sum_{i=1}^{n} e_{i}^{0}$, is given, and the amount is set by the regulator. We start by analyzing the firm's incentives to comply and the choice of optimal emissions and reported emissions. After that, we study the aggregate demand for permits. The necessary and sufficient conditions for the firm's problem are

$$
\begin{array}{r}
\pi_{i}^{\prime}\left(e_{i}\right)-S_{i}^{\prime}\left(v_{i}\right)+\lambda_{i}=0 \\
S_{i}^{\prime}\left(v_{i}\right)-p-\lambda_{i}=0 \\
\lambda_{i} \geq 0, v_{i} \geq 0, v_{i} \lambda_{i}=0 .
\end{array}
$$

It is well known that the necessary and sufficient condition for compliance is $S_{i}^{\prime}(0) \geq p$. Therefore, we have two cases which define the permit demand of firm $i$ :

Case 1: If firm $i$ is compliant, that is, if $S_{i}^{\prime}(0) \geq p$, the actual emissions satisfy equation $\pi_{i}^{\prime}\left(e_{i}\right)=p$, and $e_{i}=\hat{e}_{i}$. The demand for permits is therefore $\hat{e}_{i}=\pi_{i}^{\prime-1}(p)$, where $\pi^{\prime-1}$ is the inverse of $\pi_{i}^{\prime}$.

Case 2: If firm $i$ is noncompliant, that is, if $S_{i}^{\prime}(0)<p$, the actual emissions are given by equation $\pi_{i}^{\prime}\left(e_{i}\right)=p$, and $e_{i}>\hat{e}_{i}$. In this case the actual emissions are $e_{i}=\pi_{i}^{\prime-1}(p)$, and the violation is $v_{i}=S_{i}^{\prime-1}(p)$. Therefore, the emission report or the demand for permits is $\hat{e}_{i}=\pi_{i}^{\prime-1}(p)-S_{i}^{\prime-1}(p)$. Thus, $\hat{e}_{i}=F_{i}^{-1}(p)$ (or $F_{i}\left(\hat{e}_{i}\right)=p$ ), where we have defined $F_{i}^{-1}:=\pi_{i}^{\prime-1}-S_{i}^{\prime-1}$. Note that $F_{i}^{\prime-1}<0$, since $\pi_{i}^{\prime}<0$ and $S_{i}^{\prime}>0$. 
From cases 1 and 2 we see that the firm's actual and reported emissions are strictly decreasing in the permit price. Figure 1 illustrates the permit demand and violation of a single firm.

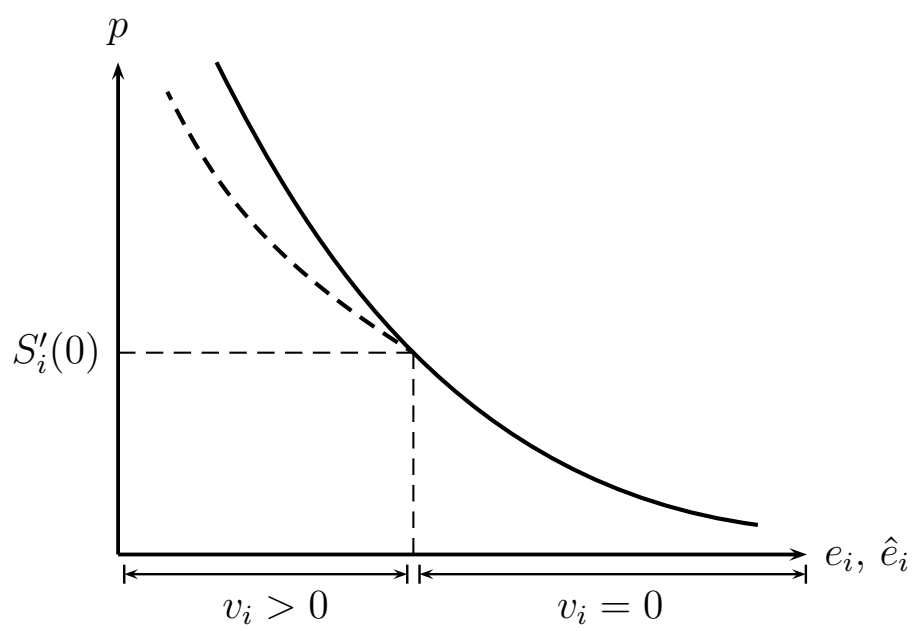

Figure 1: Permit demand and permit violation of a single firm $i$. When the permit price is higher than $S^{\prime}(0)$, the firm is noncompliant, and the permit demand is given by the dashed curve. If the price is lower than $S^{\prime}(0)$, the permit demand is given by the solid curve. The actual emissions are given by the solid curve. 
We now know the permit demand of every firm which is crucial for part 1 of Definition 1. The key role was played by the numbers $S_{i}^{\prime}(0)$. Following the second part of the definition, we add up the firms' permit demands found in part 1, and find the equilibrium permit price using the market clearing condition. In this part also, the numbers $S_{i}^{\prime}(0)$ play the key role. From now on we assume that $S_{i}^{\prime}(0) \neq S_{j}^{\prime}(0), j \neq i$, or that the firms' understanding of the marginal expected penalty at zero violations differ. ${ }^{14}$ Therefore, possibly after the renumeration of the firms, we have

$$
0<S_{1}^{\prime}(0)<S_{2}^{\prime}(0)<\ldots<S_{n}^{\prime}(0)
$$

The aggregate demand is $\sum_{i=1}^{n} \hat{e}_{i}=: \hat{E}$. Figure 2 describes the outcome for $n=2$.

\footnotetext{
${ }^{14}$ Perhaps because firm's subjective auditing probability depends on parameters, that are characteristic to that firm such as its stakeholders or its geographical distance to the regulator.
} 


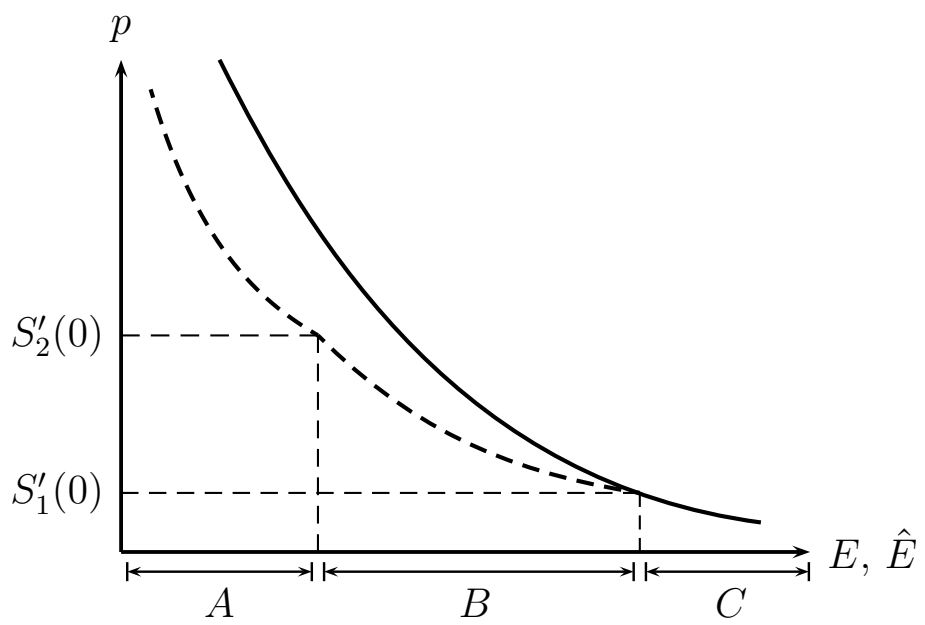

Figure 2: The aggregate demand for $n=2$. On interval $C$ the demand is given by the solid curve, but on intervals $A$ and $B$ it is given by the dashed curve. If the total initial allocation is set on interval $C$, every firm complies. If it is set on $B$, firm 1 is noncompliant, and if it is set on $A$, both of the firms are noncompliant. The actual total emission level is always given by the solid curve.

Given (6), the total initial allocation of permits defines the number of compliant firms at equilibrium. Since the regulator is unaware of (6), it is possible that some of the firms are noncompliant. If the numbers in (6), or the smallest of them, can take any possible (small but positive) values, the regulation is only second-best regulation. Even if the regulator draws up an estimate of (6) and of the functions $S_{i}$ and adjusts the total initial allocation accordingly, it is still possible that $E^{0}$ is set in a way that some of the firms are noncompliant.

We next characterize the price signal the firms receive; in particular, it is essential to study the equilibrium permit price and its relation to the number of compliant firms. This is an important ingredient of the results related to the welfare difference between the instruments. From Figure 2 it is relatively clear that the equilibrium permit price is increasing in the number of firms complying, as known since Malik (1990), who finds that the equilibrium permit price can be larger or smaller (and with the assumptions used here 
is indeed smaller) in a market with noncompliant firms than in a market with otherwise identical compliant firms.

Lemma 1. Let $p_{n-k}$ be the equilibrium permit price with $k$ noncompliant firms. Then $p_{n-k}>p_{n-(k+1)}$ for all $k=0, \ldots, n-1$, that is, the equilibrium permit price is strictly increasing in the number of compliant firms.

Proof. See Appendix A.1.

This result is very intuitive. As the number $k$ decreases, that is, as more firms comply, the permit price increases, since fewer noncompliant emission reports mean a higher demand for permits. Malik (2002) and Arguedas et al. (2010) essentially derive the same result as in Lemma 1, although in different contexts. Furthermore, our result contains a slight further insight: we find a monotonic relationship between the equilibrium permit price and the number of firms complying, therefore sharpening the previous results.

The fact that the equilibrium permit price is increasing in the number of compliant firms implies that the actual emission level of an individual firm is greater under noncompliance than under compliance. ${ }^{15}$ Although emission reductions are made in a cost-efficient fashion, this implies that total emissions are larger in an equilibrium where there are noncompliant firms than in one without them.

Next we analyze the emission tax. The problem of the firm is to

$$
\max _{\left\{e_{i}, \hat{e}_{i}\right\}} \Pi_{i}^{t}=\max _{\left\{e_{i}, \hat{e}_{i}\right\}}\left\{\pi_{i}\left(e_{i}\right)-t \hat{e}_{i}-S_{i}\left(v_{i}\right)\right\}
$$

\footnotetext{
${ }^{15}$ This follows from the concavity of the benefit function: Assume that firm $i$ is compliant when there are $n-k$ compliant firms and noncompliant when there are $n-(k+1)$ compliant firms. The other firms' behavior between compliance and noncompliance is fixed. Then

$$
\pi_{i}^{\prime}\left(e_{i}^{h}\right)=p_{n-k}>p_{n-(k+1)}=\pi_{i}^{\prime}\left(e_{i}^{d}\right),
$$

where the last equation follows after summing equations (3) and (4). The (strict) concavity of the benefit function $\pi$ implies then that $e_{i}^{h}<e_{i}^{d}$.
} 
subject to $v_{i} \geq 0$. The necessary and sufficient conditions for a solution are

$$
\begin{array}{r}
\pi_{i}^{\prime}\left(e_{i}\right)-S_{i}^{\prime}\left(v_{i}\right)+\lambda=0 \\
-t+S_{i}^{\prime}\left(v_{i}\right)-\lambda=0 \\
\lambda \geq 0, v_{i} \geq 0, \lambda v_{i}=0 .
\end{array}
$$

By adding equations (8) and (9), we obtain $\pi_{i}^{\prime}\left(e_{i}\right)=t$, which implies the first important difference between an emission tax and emissions trading: under an emission tax every firm chooses the same level of actual emissions whether or not it is compliant. This well known observation is important for the welfare comparison (as is Lemma 1), and therefore we write the result as a lemma. ${ }^{16}$

Lemma 2. Under an emission tax the actual emissions are independent of the compliance status of the firms.

As Sandmo (2002) notes related to emission taxes, the changes in the probability of auditing and penalties affect only the reported emissions, not the actual emissions. What he does not discuss is that with emissions trading these changes may affect the actual emissions through changes in the equilibrium permit price. For example, let $a$ be the number of firms the regulator audits, and assume that the expected penalty function is affected by this number. Then changes in $a$ may affect the number of noncompliant firms (through condition $S_{i}^{\prime}(0 ; a) \geq p$ ) and the equilibrium permit price, as explained in Lemma 1. The change in the price affects the level of actual emissions.

Next we consider the main point of this section, namely the welfare difference between an emission tax and emissions trading under noncompliance. To this end we must define the regulator's objective function or the social welfare function. This function is the difference between the firms' profit from emissions and the social damage function $D$

\footnotetext{
${ }^{16}$ The result in the lemma has also been observed, for example, in Sandmo (2002).
} 
(with $D^{\prime}>0$ and $\left.D^{\prime \prime}>0\right),{ }^{17}$

$$
\sum_{i=1}^{n} \pi_{i}\left(e_{i}\right)-D(E)
$$

First we assume that the regulator chooses the tax level or the total initial allocation of permits under the assumption that every firm is compliant. ${ }^{18}$ We drop this assumption later, when we modify the welfare function by subtracting enforcement and sanctioning costs from it. The first-best choice of emission tax is at the level that satisfies equation $t=D^{\prime}(E)$, where $E$ is the level of emissions that maximizes (11) and defines the initial allocation of permits. Then

$$
\pi_{i}^{\prime}\left(e_{i}\right)=D^{\prime}(E) \quad \text { for all } i \text {. }
$$

The main result of this section is

Proposition 1. The welfare under the emission tax is higher than or equal to the welfare under emissions trading, when the tax rate and the initial allocation of permits are chosen according to their first-best levels and when the regulator assumes full-compliance.

Proof. By Lemma 1 the equilibrium permit price is increasing in the number of compliant firms. This, together with how the tax is set, gives

$$
t=p_{n}>p_{n-1}>\ldots>p_{0}
$$

where $p_{n-k}$ is the equilibrium permit price with $k=0, \ldots, n$ noncompliant firms. Thus, whatever the level of compliance is, the tax is always greater than or equal to the equilibrium permit price. If even one noncompliant firm exists, the tax is greater than the equilibrium permit price.

\footnotetext{
${ }^{17}$ The strict convexity of $D$ is not actually needed for the main results.

${ }^{18}$ This assumption is sometimes used in the literature (van Egteren and Weber (1996); Malik (2002)). It is possible, for example, that the regulator believes that the firms see the probability of auditing objectively and that the enforcement is set such that $S_{i}^{\prime}(0) \geq p$ holds for every firm.
} 
$1^{\circ}$ Assume that all firms comply or equivalently $k=0$. Then the welfare is the same for both instruments.

$2^{\circ}$ Assume next that there are $n-k, k=1, \ldots, n$, compliant firms. Denote the actual emissions when there are $n-k$ compliant firms with $e_{i}(p)$ for some price $p$. The regulator's objective (11) depends on the actual emissions $e_{i}$, which themselves depend on the price $p$ (which can, of course, also be tax $t$ ). Therefore, define function $Z: \mathbb{R}_{+} \rightarrow \mathbb{R}$ with ${ }^{19}$

$$
Z(p)=\sum_{i=1}^{n} \pi_{i}\left(e_{i}(p)\right)-D\left(\sum_{i=1}^{n} e_{i}(p)\right) .
$$

Since $Z$ is continuously differentiable, and $t>p_{n-k}$, there exists by the mean-value theorem a price $\left.p^{m} \in\right] p_{n-k}, t[$ such that equation

$$
\frac{Z(t)-Z\left(p_{n-k}\right)}{t-p_{n-k}}=Z^{\prime}\left(p^{m}\right)
$$

holds. If we show that $Z^{\prime}\left(p^{m}\right)>0$, we know by equation (15) that $Z(t)>Z\left(p_{n-k}\right)$. We evaluate the sign of $Z^{\prime}\left(p^{m}\right)$ using the following properties. From the fact that actual emissions are decreasing in price, we have

$$
p^{m}<t \Rightarrow e_{i}(t)<e_{i}\left(p^{m}\right) \quad \text { for all } i
$$

Using this and Lemma 2, we have

$$
e_{i}^{h}(t)=e_{i}(t)<e_{i}\left(p^{m}\right) \quad \text { for all } i
$$

From the assumptions about functions $\pi_{i}$ and $D$, it then follows that

$$
\pi_{i}^{\prime}\left(e_{i}\left(p^{m}\right)\right)<\pi_{i}^{\prime}\left(e_{i}(t)\right)=\pi_{i}^{\prime}\left(e_{i}^{h}(t)\right) \quad \text { for all } i
$$

and

$$
D^{\prime}\left(\sum_{i=1}^{n} e_{i}\left(p^{m}\right)\right)>D^{\prime}\left(\sum_{i=1}^{n} e_{i}(t)\right)=D^{\prime}\left(\sum_{i=1}^{n} e_{i}^{h}(t)\right)
$$

\footnotetext{
${ }^{19}$ Note that the argument of function $D$ is not the total initial allocation, but the total actual emissions at price $p$.
} 
Using these, we can evaluate $Z^{\prime}\left(p^{m}\right)$ as follows.

$$
\begin{aligned}
Z^{\prime}\left(p^{m}\right) & =\sum_{i=1}^{n} \pi_{i}^{\prime}\left(e_{i}\left(p^{m}\right)\right) \frac{\partial e_{i}\left(p^{m}\right)}{\partial p}-D^{\prime}\left(\sum_{i=1}^{n} e_{i}\left(p^{m}\right)\right) \sum_{i=1}^{n} \frac{\partial e_{i}\left(p^{m}\right)}{\partial p} \\
& >\sum_{i=1}^{n} \pi_{i}^{\prime}\left(e_{i}^{h}(t)\right) \frac{\partial e_{i}\left(p^{m}\right)}{\partial p}-D^{\prime}\left(\sum_{i=1}^{n} e_{i}^{h}(t)\right) \sum_{i=1}^{n} \frac{\partial e_{i}\left(p^{m}\right)}{\partial p} \\
& =D^{\prime}\left(\sum_{i=1}^{n} e_{i}^{h}(t)\right) \sum_{i=1}^{n} \frac{\partial e_{i}\left(p^{m}\right)}{\partial p}-D^{\prime}\left(\sum_{i=1}^{n} e_{i}^{h}(t)\right) \sum_{i=1}^{n} \frac{\partial e_{i}\left(p^{m}\right)}{\partial p} \\
& =0
\end{aligned}
$$

where equality (19) follows from (12), that is, from $\pi_{i}^{\prime}\left(e_{i}^{h}(t)\right)=D^{\prime}\left(\sum_{i=1}^{n} e_{i}^{h}(t)\right)$ for all $i$. Then using equation (15), we have $Z(t)>Z\left(p_{n-k}\right)$, that is, a tax yields higher social welfare than emissions trading.

Proposition 1 can be interpreted as follows (see Figure 3). In the case of an emission tax, the marginal cost of compliance is fixed and independent of the number of compliant firms. However, in the case of emissions trading, the permit price depends on the compliance level of the firms. This is the main difference between the instruments in this context. If the regulator is able to set the emission tax at the right level, the actual emissions of the firms are at the same level as the socially optimal emission levels, and the marginal benefits from emissions are equalized. For emissions trading, the actual emissions differ from the socially optimal levels since the compliance level of the firms affects the permit price, which is lower under noncompliance than under compliance. Then it is clear that the social welfare differs between the two instruments. This proposition has a policy implication in favor of taxes over permits when some of the firms are noncompliant. Note that this proposition also holds when the probability of auditing is constant in the firms' violations. An immediate corollary for the result is that the welfare difference in favor of taxes is increasing in the number of noncompliant firms, although the size of the welfare difference is nevertheless unknown. 


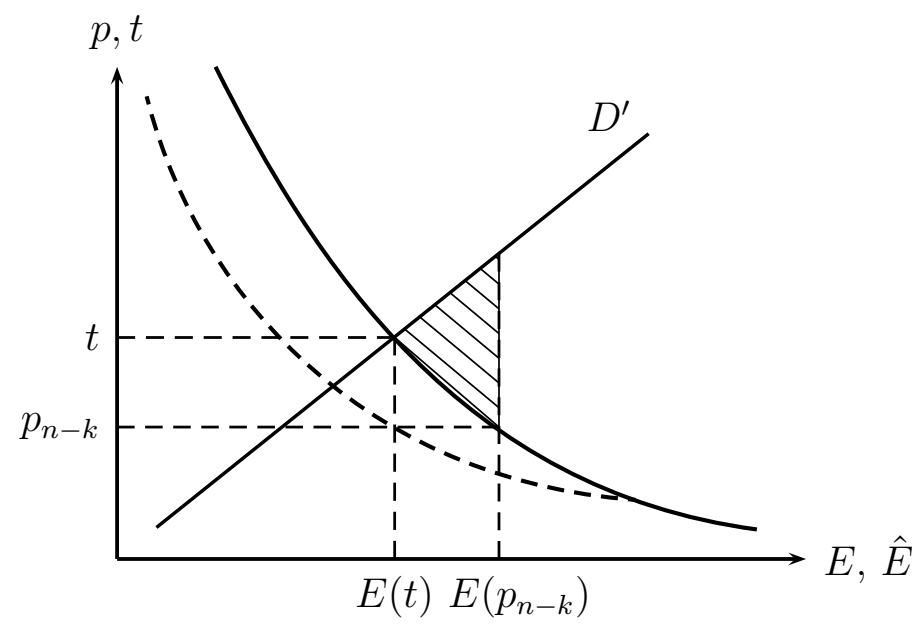

Figure 3: The shaded area describes the welfare difference between the instruments.

Are there ways to overcome the welfare loss caused by noncompliance in the emissions trading scheme? Intuitively, if the regulator knows that some firms are noncompliant given the applied enforcement scheme, the regulator might be tempted to adjust the initial allocation of permits in a way that the realized permit price equals the tax. If successful, this would result in the same actual emissions level and social welfare for both instruments. ${ }^{20}$ The problem with this argument is that the optimal adjustment of the initial allocation downwards requires that the regulator knows the marginal expected penalty functions.

The result should also be compared to Montero (2002), in which the author finds that both emission tax and permits result in equal social welfare. The sharp difference between the results stems from different assumptions about what the regulator knows about the probability of auditing. Furthermore, in Montero's paper the auditing probability is objective, which in part allows the adjustment for the initial allocation of permits to induce the same equilibrium permit price as the optimal emission tax. In the model

\footnotetext{
${ }^{20} \mathrm{~A}$ similar argument is also given in the analysis made by Arguedas et al. (2010) in the case of investing in abatement technology.
} 
developed in this study this kind of adjustment is not possible because the demand for permits when some of the firms are noncompliant is unknown to the regulator due to subjective beliefs regarding monitoring (although the range of possible emission levels is known to the regulator).

\subsection{Welfare analysis in the presence of enforcement and sanc- tioning costs}

The welfare function used above includes only benefits and damages from emissions. However, enforcement is costly, as is sanctioning of the guilty firms. These costs should be included in the welfare function. It can be argued that more firms would be sanctioned with an emission tax than with emissions trading: from Lemma 1 we know that when some of the firms are noncompliant $t>p_{n-k}$, which together with the necessary and sufficient condition for noncompliance $\left(S_{i}^{\prime}(0)<t\right.$ in the case of taxes) implies that there may be more noncompliant firms with a tax than with emissions trading. This means that the sanctioning costs can be greater with a tax, if a higher number of noncompliant firms means a higher number of guilty firms (with a given auditing level). Also, the regulator was assumed to choose the instruments with a predetermined enforcement level as if the firms are compliant. These issues raise the question of whether or not the result in Proposition 1 holds if we drop these assumptions. To answer this question, we postulate that the enforcement costs are a function of the number of audited firms and that the sanctioning costs are a function of the number of noncompliant firms identified through audits.

First, we introduce some additional notation. Let $a^{j}, j=p, t$, where $p$ means emissions trading and $t$ means an emission tax, denote the number of firms audited with instrument $j$. Enforcement costs are a function of the number of audited firms, $\mathcal{E}\left(a^{j}\right)$, with the 
property

$$
\mathcal{E}\left(a^{j}+1\right)-\mathcal{E}\left(a^{j}\right)>0, \quad \text { for all } a^{j} \in\{0, \ldots, n-1\} .
$$

That is, enforcement costs are increasing in the number of audited firms. ${ }^{21}$

Next we define the sanctioning costs following closely Polinsky and Shavell (1992). ${ }^{22}$ The sanctioning costs are defined to be a function of the number of noncompliant firms that are found guilty of excess emissions during audits. Only a fraction of the audited firms are noncompliant and therefore influence the sanctioning costs. The size of the fraction depends on the incentives of the firms to be noncompliant (recall again that the incentives to be compliant are given by the inequality $\left.S_{i}^{\prime}(0) \geq p\right)$.

To operationalize this, we assume that the regulator has an estimate of the expected penalty functions $S_{i}$. In particular, we assume that the regulator knows that these functions depend on the absolute violations $v_{i}$ and that they are increasing and strictly convex in violations. Also, we let $S_{i}^{\prime}(0)$ depend on the number of firms audited such that a higher level of auditing means a higher marginal expected penalties at zero violations. We use the notation $S_{i}^{\prime}\left(0 ; a^{j}\right)$.

Let the cost of sanctioning one firm be a constant $s$. Then the total sanctioning cost of every noncompliant firm is

$$
s I^{j}
$$

where $I^{j}$, the number of noncompliant firms, is the sum of the indicator function values (a noncompliant firm is given a 1 and a compliant firm is given a 0 ) over all the firms.

\footnotetext{
${ }^{21} \mathrm{We}$ could let the enforcement costs depend continuously and smoothly on the level of auditing, namely, we could let the enforcement costs be a function $\mathcal{E}\left(a^{j}\right)$ with $\mathcal{E}^{\prime}\left(a^{j}\right)>0$, where $a^{j} \in[0,1)$ is the proportion of firms audited. The discrete choice is more intuitive, though.

${ }^{22}$ Stranlund (2007) has analyzed enforcement and sanctioning costs in an emissions trading model but uses an objective auditing probability. Also, Stranlund and Moffitt (2014) include these costs in their analysis on hybrid policies and noncompliance, but they too use an objective auditing probability.
} 
That is, $I^{j}=\sum_{i=1}^{n} f(i)$,

$$
f(i)=\left\{\begin{array}{l}
\left.1, \text { if } v_{i}>0, \quad \text { (equivalently if } S_{i}^{\prime}\left(0 ; a^{j}\right)<j\right) \\
\left.0, \text { if } v_{i}=0, \quad \text { (equivalently if } S_{i}^{\prime}\left(0 ; a^{j}\right) \geq j\right)
\end{array}\right.
$$

Note that $I^{j}$ depends on $a^{j}$ : as the number of audited firms decreases, the number of noncompliant firms (weakly) increases. Since only $a^{j}$ firms of $n$ firms are audited, the expected sanctioning costs are then

$$
\mathcal{S}\left(a^{j}\right)=\frac{a^{j}}{n} s I^{j}
$$

The expected sanctioning costs are increasing in the number of firms identified as noncompliant. The expected sanctioning cost function in (23) is similar to the one in Polinsky and Shavell (1992): the auditing probability (actually used by the regulator) times the constant cost times the number of noncompliant firms. With this notation the regulator's objective function (or the welfare function) reads

$$
W=\sum_{i=1}^{n} \pi_{i}\left(e_{i}\right)-D(E)-\mathcal{S}(a)-\mathcal{E}(a) .
$$

The problem for the regulator is to choose $t$ (or $E^{0}$ ) and $a^{t}$ (or $a^{p}$ ) to maximize (24) subject to the optimal behavior of the firms. ${ }^{23}$ These settings are used to show that the result in Proposition 1 continues to hold:

Proposition 2. The welfare under an emission tax is higher than or equal to the welfare under emissions trading even when sanctioning costs and enforcement costs are included in the welfare criterion and the regulator is allowed to choose the instruments and the number of audited firms optimally.

Proof. Denote $V(E)=\sum_{i=1}^{n} \pi_{i}\left(e_{i}\right)-D(E)$, and consider the tax first. The optimal emission choice of any firm $i$ is given by the equation $\pi_{i}^{\prime}\left(e_{i}\right)=t$. If the tax is set such

\footnotetext{
${ }^{23}$ The penalty function is given. Of course, at least the unit penalty can also be chosen by the regulator (as well as many other factors). We abstract away from these possibilities.
} 
that $t=D^{\prime}(E)$, the emission level is at its first-best level. This choice for the tax level and $a^{t}=0$ maximize $W$.

With emissions trading, the actual total emissions do not maximize $V(E)$ when firstbest regulation level is used (and if $a^{p}=0$ and if at least one firm is noncompliant). Therefore, in order to decrease $E$ (which is too high when some of the firms are noncompliant), the regulator has two mutually nonexclusive choices: audit more firms or adjust the total initial allocation of permits downwards.

1. Inspecting more firms means that $a^{p}>a^{t}=0$, and $\mathcal{S}\left(a^{p}\right)+\mathcal{E}\left(a^{p}\right)>\mathcal{S}(0)+\mathcal{E}(0)$, implying that the welfare is greater with a tax than with permits.

2. The second possibility for the regulator is to let $a^{p}=0$ and decrease $E^{0}$, but since the true functions $S_{i}$ and the numbers (6) are unknown to the regulator, this can yield at best the same welfare as a tax (the same welfare can be achieved only with the correct estimation of the aggregate permit demand function).

3. The third possibility, the adjustment of both numbers, yields a lower level of welfare than an emission tax since $a^{p}>0$.

One implication of this result is that the sanctioning and enforcement costs play a small role in the comparison of an emission tax and emissions trading. The result hinges essentially on the fact that the regulator does not need information on $S_{i}$ to set the tax optimally to the first-best level. It is therefore interesting to analyze other possibilities for modeling the expected penalties, which is done in the next section.

Note finally that if the choice in (24) is constrained by $a^{j} \geq 1$, Proposition 2 may change. When $a^{j} \geq 1$, the optimal choice with an emission tax is $t=D^{\prime}(E)$ and $a^{t}=1$, which gives the welfare $V(E(t))-\mathcal{S}(1)-\mathcal{E}(1)$. For emissions trading, it may be the case that the estimate of the functions $S_{i}$ is so good that $V(E(p))$ is close enough to $V(E(t))$ with $a^{p}=1$ to reverse the welfare ranking. This happens if $\frac{1}{n} s\left(I^{t}-I^{p}\right)$ is greater than 
$V(E(t))-V(E(p))$. A necessary condition for this reversion is

$$
s>V(E(t))-V(E(p))
$$

or that the unit cost of sanctioning is greater than the "direct" welfare gain from using an emission tax instead of emissions trading. Therefore, for a "small" unit cost of sanctioning, this reversion is impossible. However, with no sanctioning costs, taxes yield a higher level of welfare even with the constraint $a^{j} \geq 1$.

\section{A welfare analysis under noncompliance: Relative violations}

We assume next, as in Hatcher $(2005 ; 2012)$, that the expected penalty function depends on the relative violations, $\frac{e_{i}-\hat{e}_{i}}{\hat{e}_{i}}$. This could be due to the fact that the subjective probability of auditing depends on the relative violations. The firm's objective function is

$$
\Pi_{i}^{p}\left(e_{i}, \hat{e}_{i}\right)=\pi_{i}\left(e_{i}\right)-p\left(\hat{e}_{i}-e_{i}^{0}\right)-S_{i}\left(\frac{e_{i}-\hat{e}_{i}}{\hat{e}_{i}}\right) .
$$

The necessary conditions for the firm's maximization problem are

$$
\begin{array}{r}
\pi_{i}^{\prime}\left(e_{i}\right)-S_{i}^{\prime}\left(\frac{e_{i}-\hat{e}_{i}}{\hat{e}_{i}}\right) \frac{1}{\hat{e}_{i}}+\lambda_{i}=0 \\
S_{i}^{\prime}\left(\frac{e_{i}-\hat{e}_{i}}{\hat{e}_{i}}\right) \frac{e_{i}}{\hat{e}_{i}^{2}}-p-\lambda_{i}=0 \\
\lambda_{i} \geq 0, v_{i} \geq 0, v_{i} \lambda_{i}=0 .
\end{array}
$$

From these conditions we find a necessary and sufficient condition for compliance, which is interesting as such since it differs from the condition with absolute violations.

Lemma 3. Firm $i$ is compliant if and only if $S_{i}^{\prime}(0) \frac{1}{e_{i}} \geq p$.

Proof. See Appendix A.2. 
The emission level has an influence on the compliance decision of the firm: the greater the amount of the firm's emissions, the less likely it is that the firm complies (for a given permit price). For the sake of argument assume that the firm size is equivalent with its emissions level and that $S_{i}^{\prime}(0)=S_{j}^{\prime}(0)$ for all $i$ and $j$. Then it follows that larger firms are more likely to be noncompliant, which may be interpreted as an additional reason to audit larger firms.

We want to show that the equilibrium permit price is increasing in the number of compliant firms also when the marginal expected penalties depend on the relative violations. For this we need to show that the reported emissions of a noncompliant firm are strictly decreasing in the permit price.

Lemma 4. Suppose that the expected penalties depend on the relative violations.

(i) The optimal reported emissions of a noncompliant firm are strictly decreasing in the permit price.

(ii) The equilibrium permit price is strictly increasing in the number of compliant firms.

Proof. See Appendix A.3.

If the regulator uses an emission tax as the instrument, the necessary conditions for the optimum are similar to conditions (27)-(29) above. With relative violations the result in Lemma 2 changes to

Lemma 5. Suppose that the expected penalties depend on relative violations and that an emission tax is used. Then the actual emissions are smaller when the firm is compliant than when it is noncompliant.

Proof. See Appendix A.4.

The result in Proposition 1 stays intact with relative violations, as we demonstrate next. 
Proposition 3. Suppose that the expected penalties depend on relative violations. Then the welfare under an emission tax is higher than or equal to the welfare under emissions trading, when the tax rate and the initial allocation of permits are chosen according to their first-best levels and when the regulator assumes full-compliance.

Proof. We modify the proof of Proposition 1 to the present context. Only $2^{\circ}$ must be reanalyzed. Lemma 5 alters equations (16)-(18), which in the present context are replaced by equations

$$
\begin{aligned}
e_{i}^{h}(t) & \leq e_{i}(t) \leq e_{i}\left(p^{m}\right) \quad \text { for all } i \\
\pi_{i}^{\prime}\left(e_{i}\left(p^{m}\right)\right) & \leq \pi_{i}^{\prime}\left(e_{i}(t)\right) \leq \pi_{i}^{\prime}\left(e_{i}^{h}(t)\right) \quad \text { for all } i, \\
D^{\prime}\left(\sum_{i=1}^{n} e_{i}\left(p^{m}\right)\right) & \geq D^{\prime}\left(\sum_{i=1}^{n} e_{i}(t)\right)>D^{\prime}\left(\sum_{i=1}^{n} e_{i}^{h}(t)\right) .
\end{aligned}
$$

Note, that the first inequality can be an equality for some of the firms, namely for those that are compliant. It is a strict inequality for noncompliant firms. Since $\pi_{i}^{\prime}\left(e_{i}^{d}\right)<t$ and $t=\pi_{i}^{\prime}\left(e_{i}^{h}\right)$ for all $i$ we have that

$$
\pi_{i}^{\prime}\left(e_{i}\right) \leq t \quad \text { for all } i
$$

Using these, we can evaluate $Z^{\prime}\left(p^{m}\right)$ as follows.

$$
\begin{aligned}
Z^{\prime}\left(p^{m}\right) & =\sum_{i=1}^{n} \pi_{i}^{\prime}\left(e_{i}\left(p^{m}\right)\right) \frac{\partial e_{i}\left(p^{m}\right)}{\partial p}-D^{\prime}\left(\sum_{i=1}^{n} e_{i}\left(p^{m}\right)\right) \sum_{i=1}^{n} \frac{\partial e_{i}\left(p^{m}\right)}{\partial p} \\
& \geq \sum_{i=1}^{n} \pi_{i}^{\prime}\left(e_{i}(t)\right) \frac{\partial e_{i}\left(p^{m}\right)}{\partial p}-D^{\prime}\left(\sum_{i=1}^{n} e_{i}(t)\right) \sum_{i=1}^{n} \frac{\partial e_{i}\left(p^{m}\right)}{\partial p} \\
& >\sum_{i=1}^{n} t \frac{\partial e_{i}\left(p^{m}\right)}{\partial p}-D^{\prime}\left(\sum_{i=1}^{n} e_{i}^{h}(t)\right) \sum_{i=1}^{n} \frac{\partial e_{i}\left(p^{m}\right)}{\partial p} \\
& =0
\end{aligned}
$$

where equality (37) follows from from $t=D^{\prime}\left(\sum_{i=1}^{n} e_{i}^{h}(t)\right)$. The proof is completed by similar arguments as in the proof of Proposition 1 . 
Therefore, the most important result for absolute violations carries over to the case of relative violations: under noncompliance an emission tax yields a higher level of welfare than emissions trading, if the regulator has set the level of instruments to their first-best levels. This result is, of course, conditional on the choice of the welfare function and on the way the regulator chooses the instruments. Generalizing the result in the same directions as with absolute violations seems to be a difficult thing to do. ${ }^{24}$ The main reason for this is that the actual emissions under a tax depend on whether or not the firm is compliant.

One implication of the analysis is nevertheless that with absolute violations, the sanctioning and enforcement costs play a very small role in the welfare comparison between the instruments; with a tax these costs can be minimized by the regulator without affecting the first-best choice of actual total emissions. But with relative violations this is not possible even with a tax. However, in the monitoring and enforcement literature absolute violations have been the more common modeling choice.

\section{Conclusions}

We have studied the welfare difference between an emission tax and emissions trading under noncompliance, and found that in the case of absolute violations taxes yield a higher welfare than permits irrespective of the inclusion of enforcement and sanctioning costs in the welfare criterion. The results indicate that at least for the case of absolute violations the nice welfare equivalence of the two instruments does not hold when some of the firms are noncompliant. Both instruments are efficient in the sense that the marginal abatement cost equals the marginal cost of compliance, but with permits, the marginal cost of compliance depends on the compliance pattern of the firms, thus affecting the actual emission level and therefore the welfare level.

The subjective probability of auditing can be seen as a sufficient condition for this

\footnotetext{
${ }^{24}$ Numerical analysis may be useful in this case.
} 
result, but it is by no means necessary. Indeed, this result can be obtained even with objective auditing probabilities if some of the firms are noncompliant. This could be due to the simple fact that it is not always the case that noncompliant firms must pay the penalty that the regulator has set, as has happened in some programs (see Heyes 1998). As the (subjective) auditing functions used in the model are, of course, not of the most general type that one may wish to use, a more general model would be of interest to analyze. In addition, we have not analyzed the size of the welfare difference and whether or not it is large enough to matter in practice. 
Acknowledgments: The author thanks Markku Ollikainen and Essi Eerola for their helpful comments. Financial support from the OP-Pohjola Group Research Foundation is gratefully acknowledged.

\section{Appendices}

\section{A.1}

Proof of Lemma 1.

Fix $k=0, \ldots, n-1$ and define a function $F: \mathbb{R}_{+} \rightarrow \mathbb{R}$ with

$$
F(p)=\sum_{i=1}^{k} \hat{e}_{i}(p)+\sum_{i=k+1}^{n} e_{i}^{h}(p)-E^{0} .
$$

The function $F$ is strictly decreasing in $p$ since emissions reports and actual emissions are strictly decreasing in $p$. Since $p_{n-k}$ is the equilibrium price with $k$ noncompliant firms, we have $F\left(p_{n-k}\right)=0$.

We evaluate the difference $F\left(p_{n-k}\right)-F\left(p_{n-(k+1)}\right)$ as follows.

$$
\begin{aligned}
F\left(p_{n-k}\right)-F\left(p_{n-(k+1)}\right) & =\sum_{i=1}^{k} \hat{e}_{i}\left(p_{n-k}\right)+\sum_{i=k+1}^{n} e_{i}^{h}\left(p_{n-k}\right)-E^{0} \\
& -\sum_{i=1}^{k} \hat{e}_{i}\left(p_{n-(k+1)}\right)-\sum_{i=k+1}^{n} e_{i}^{h}\left(p_{n-(k+1)}\right)+E^{0} \\
& =-\sum_{i=1}^{k} \hat{e}_{i}\left(p_{n-(k+1)}\right)-\sum_{i=k+1}^{n} e_{i}^{h}\left(p_{n-(k+1)}\right)+E^{0} \\
& <-\sum_{i=1}^{k+1} \hat{e}_{i}\left(p_{n-(k+1)}\right)-\sum_{i=k+2}^{n} e_{i}^{h}\left(p_{n-(k+1)}\right)+E^{0}=0,
\end{aligned}
$$

where the inequality follows from the definition of noncompliant behavior, that is, from the inequality $\hat{e}_{i}(p)<e_{i}^{h}(p)$ for any $p$ and for any noncompliant firm, and the last equality follows from the market clearing condition for $k+1$ noncompliant firms.

Now we show that $p_{n-k}>p_{n-(k+1)}$ by contradiction. Assume that $p_{n-k} \leq p_{n-(k+1)}$ holds. If $p_{n-k}=p_{n-(k+1)}$, then $F\left(p_{n-k}\right)=F\left(p_{n-(k+1)}\right)$, contradicting (A.39), and if 
$p_{n-k}<p_{n-(k+1)}$, then $F\left(p_{n-k}\right)>F\left(p_{n-(k+1)}\right)$, since $F$ is strictly decreasing, which again contradicts (A.39). To conclude, the assumption $p_{n-k} \leq p_{n-(k+1)}$ leads to a contradiction implying that the inequality $p_{n-k}>p_{n-(k+1)}$ holds.

\section{A.2}

Proof of Lemma 3.

If $v_{i}=0$, we have from equation (28) that $S_{i}^{\prime}(0) \frac{1}{e_{i}}=p+\lambda \geq p$. We give a proof for the other direction by showing that $v_{i}>0$ implies that $S_{i}^{\prime}(0) \frac{1}{e_{i}}<p$. When $v_{i}>0$, we have $\lambda_{i}=0$. Therefore equality

$$
S_{i}^{\prime}\left(\frac{e_{i}-\hat{e}_{i}}{\hat{e}_{i}}\right) \frac{e_{i}}{\hat{e}_{i}^{2}}=p
$$

holds. Using the strict convexity of $S_{i}$ and the inequality $e_{i}>\hat{e}_{i}$, we obtain

$$
p=S_{i}^{\prime}\left(\frac{e_{i}-\hat{e}_{i}}{\hat{e}_{i}}\right) \frac{e_{i}}{\hat{e}_{i}^{2}}>S_{i}^{\prime}\left(\frac{e_{i}-\hat{e}_{i}}{\hat{e}_{i}}\right) \frac{1}{e_{i}}>S_{i}^{\prime}(0) \frac{1}{e_{i}} .
$$

\section{A.3}

\section{Proof of Lemma 4 .}

Part (i). (We assume differentiability where ever necessary.) We first use Theorem 5 (Topkis's Theorem) in Milgrom and Shannon (1994) to show that the actual and reported emissions are nonincreasing in the permit price. The objective function $\Pi_{i}^{p}$ is supermodular in $\left(e_{i}, \hat{e}_{i}\right)$ and satisfies increasing differences in $\left(e_{i}, \hat{e}_{i} ;-p\right)$, since

$$
\begin{aligned}
\frac{\partial^{2} \Pi_{i}^{p}}{\partial e_{i} \partial \hat{e}_{i}} & =S_{i}^{\prime \prime}\left(\frac{e_{i}-\hat{e}_{i}}{\hat{e}_{i}}\right) \frac{e_{i}}{\hat{e}_{i}^{3}}+S_{i}^{\prime}\left(\frac{e_{i}-\hat{e}_{i}}{\hat{e}_{i}}\right) \frac{1}{\hat{e}_{i}^{2}}>0, \\
\frac{\partial^{2} \Pi_{i}^{p}}{\partial e_{i} \partial(-p)} & =0, \quad \text { and } \quad \frac{\partial^{2} \Pi_{i}^{p}}{\partial \hat{e}_{i} \partial(-p)}=1>0 .
\end{aligned}
$$

Therefore, $\operatorname{argmax}_{\left(e_{i}, \hat{e}_{i}\right) \in X} \Pi_{i}^{p}\left(e_{i}, \hat{e}_{i} ;-p\right)$, where $X$ is the feasible set $\left\{\left(e_{i}, \hat{e}_{i}\right) \in \mathbb{R}^{2} \mid e_{i}>\right.$ $\left.0, \hat{e}_{i}>0, e_{i}-\hat{e}_{i} \geq 0\right\}$, is nondecreasing in $-p$ or equivalently nonincreasing in $p$. In 
particular,

$$
\frac{\partial e_{i}(p)}{\partial(-p)} \geq 0
$$

Now we show that the reported emissions of a noncompliant firm are strictly decreasing in the permit price. We do this by applying the aggregation method described in Milgrom and Shannon (1994) together with Strict Monotonicity Theorem 1 (SMT1) in Edlin and Shannon (1998). Define

$$
K_{i}\left(\hat{e}_{i} ;-p\right):=\max _{e_{i}>\hat{e}_{i}} \Pi_{i}^{p}\left(e_{i}, \hat{e}_{i} ;-p\right)
$$

where $\hat{e}_{i} \in \mathbb{R}_{++}$. The function $K_{i}$ has increasing marginal returns (that is, $\frac{\partial K_{i}}{\partial \hat{e}_{i}}$ is increasing in $-p$ ), since

$$
\frac{\partial^{2} K_{i}}{\partial \hat{e}_{i} \partial(-p)}=\frac{\partial^{2} \Pi_{i}^{p}}{\partial \hat{e}_{i} \partial e_{i}} \frac{\partial e_{i}}{\partial(-p)}+1>0
$$

by (A.44). Let $-p^{\prime}>-p^{*}$ (the other case is derived similarly) and define

$$
\begin{aligned}
& \hat{e}_{i}^{*}=\underset{\hat{e}_{i} \in \mathbb{R}_{++}}{\operatorname{argmax}} K_{i}\left(\hat{e}_{i} ;-p^{*}\right) \quad \text { and } \\
& \hat{e}_{i}^{\prime}=\underset{\hat{e}_{i} \in \mathbb{R}_{++}}{\operatorname{argmax}} K_{i}\left(\hat{e}_{i} ;-p^{\prime}\right) .
\end{aligned}
$$

From the beginning of the proof we know that $\hat{e}_{i}^{\prime} \geq \hat{e}_{i}^{*}$, which can be strengthened to $\hat{e}_{i}^{\prime}>\hat{e}_{i}^{*}$ by (A.46) and by SMT1. In other words we have that $p^{\prime}<p^{*}$ implies $\hat{e}_{i}^{\prime}>\hat{e}_{i}^{*}$, as desired.

Part (ii). We can use the same reasoning as in the proof of Lemma 1, since the reported emissions (and the actual) are strictly decreasing in the permit price.

\section{A.4}

Proof of Lemma 5.

A noncompliant firm chooses its emissions and reported emissions such that

$$
\pi_{i}^{\prime}\left(e_{i}^{d}\right)-t+S_{i}^{\prime}\left(\frac{e_{i}-\hat{e}_{i}}{\hat{e}_{i}}\right)\left[\frac{e_{i}^{d}}{\hat{e}_{i}^{2}}-\frac{1}{\hat{e}_{i}}\right]=0
$$


The term in the brackets is positive, since $e_{i}^{d}>\hat{e}_{i}$. When the firm is compliant, equation $\pi_{i}^{\prime}\left(e_{i}^{h}\right)=t$ holds. Since $\pi_{i}^{\prime \prime}<0$, we have $e_{i}^{d}>e_{i}^{h}$. 


\section{References}

[1] Arguedas, C., Camacho, E., Zofío, J.L., 2010. Environmental policy instruments: technology adoption incentives with imperfect compliance. Environmental and Resource Economics 47, 261-274.

[2] Edlin, A.S., Shannon, C., 1998. Strict monotonicity in comparative statics. Journal of Economic Theory 81, 201-219.

[3] Van Egteren, H., Weber, M., 1996. Marketable permits, market power and cheating. Journal of Environmental Economics and Management 30, 161-173.

[4] Franckx, L. 2002. The use of ambient inspections in environmental monitoring and enforcement when the inspection agency cannot commit itself to announced inspection probabilities. Journal of Environmental Economics and Management 43, 71-92.

[5] Harford, J.D., 1978. Firm behavior under imperfectly enforceable pollution standards and taxes. Journal of Environmental Economics and Management 5, 26-43.

[6] Hatcher, A., 2005. Non-compliance and the quota price in an ITQ fishery. Journal of Environmental Economics and Management 49, 427-436.

[7] Hatcher, A., 2012. Market power and compliance with output quotas. Resource and Energy Economics 34, 255-269.

[8] Heyes, A.G., 1998. Making things stick: enforcement and compliance. Oxford Review of Economic Policy 14, 50-63.

[9] Keeler, A.G., 1991. Noncompliant firms in transferable discharge permit markets: some extensions. Journal of Environmental Economics and Management 21, 180189. 
[10] Macho-Stadler, I., Pérez-Castrillo, D., 2006. Optimal enforcement policy and firms' emissions and compliance with environmental taxes. Journal of Environmental Economics and Management 51, 110-131.

[11] Malik, A.S., 1990. Markets for pollution control when firms are noncompliant. Journal of Environmental Economics and Management 18, 97-106.

[12] Malik, A.S., 1992. Enforcement costs and the choice of policy instruments for controlling pollution. Economic Inquiry 30, 714-721.

[13] Malik, A.S., 2002. Further results on permit markets with market power and cheating. Journal of Environmental Economics and Management 44, 371-390.

[14] Milgrom, P., Shannon, C., 1994. Monotone comparative statics. Econometrica 62, $157-180$.

[15] Montero, J-P., 2002. Prices versus quantities with incomplete enforcement. Journal of Public Economics 85, 435-454.

[16] Polinsky, A.M., Shavell, S. 1992. Enforcement costs and the optimal magnitude and probability of fines. Journal of Law and Economics 35, 133-148.

[17] Rousseau, S., Proost, S., 2005. Comparing environmental policy instruments in the presence of imperfect compliance - a case study. Environmental and Resource Economics 32, 337-365.

[18] Rousseau, S., Proost, S., 2009. The relative efficiency of market-based environmental policy instruments with imperfect compliance. International Tax and Public Finance $16,25-42$.

[19] Rohling, M., Ohndorf, M., 2012. Prices vs. quantites with fiscal cushioning. Resource and Energy Economics 34, 169-187. 
[20] Sandmo, A., 2002. Efficient environmental policy with imperfect compliance. Environmental and Resource Economics 23, 85-103.

[21] Stranlund, J.K., Dhanda, K.K., 1999. Endogenuous monitoring and enforcement of a transferable emissions permit system. Journal of Environmental Economics and Management 38, 267-282.

[22] Stranlund, J.K., 2007. The regulatory choice of noncompliance in emissions trading programs. Environmental and Resource Economics 38, 99-117.

[23] Stranlund, J.K., Chávez, C.A., Villena, M.G., 2009. The optimal pricing of pollution when enforcement is costly. Journal of Environmental Economics and Management $58,183-191$.

[24] Stranlund, J.K., Moffitt, J.L., 2014. Enforcement and price controls in emissions trading. Journal of Environmental Economics and Management 67, 20-38.

[25] Villegas-Palacio, C., Coria, J., 2010. On the interaction between imperfect compliance and technology adoption: taxes versus tradable emissions permits. Journal of Regulatory Economics 38, 274-291. 